Published in final edited form as:

Urol Res. 2011 August ; 39(4): 303-307. doi:10.1007/s00240-010-0347-5.

\title{
Nephrolithiasis in topiramate users
}

\author{
Naim M. Maalouf, \\ Department of Internal Medicine, Charles and Jane Pak Center for Mineral Metabolism \& Clinical \\ Research, University of Texas Southwestern Medical Center, 5323 Harry Hines Blvd, Dallas, TX \\ 75390-8885, USA
}

Joshua P. Langston,

Department of Internal Medicine, Charles and Jane Pak Center for Mineral Metabolism \& Clinical Research, University of Texas Southwestern Medical Center, 5323 Harry Hines Blvd, Dallas, TX 75390-8885, USA

\section{Paul C. Van Ness, \\ Department of Neurology, University of Texas Southwestern Medical Center, Dallas, TX 75390, USA}

Orson W. Moe, and

Department of Internal Medicine, Charles and Jane Pak Center for Mineral Metabolism \& Clinical Research, University of Texas Southwestern Medical Center, 5323 Harry Hines Blvd, Dallas, TX 75390-8885, USA

\section{Khashayar Sakhaee}

Department of Internal Medicine, Charles and Jane Pak Center for Mineral Metabolism \& Clinical Research, University of Texas Southwestern Medical Center, 5323 Harry Hines Blvd, Dallas, TX 75390-8885, USA

Naim M. Maalouf: Naim.Maalouf@utsouthwestern.edu

\section{Abstract}

Topiramate is a neuromodulatory agent increasingly prescribed for a number of neurological and non-neurological indications. Topiramate-treated patients are at risk for nephrolithiasis due to hypocitraturia and high urine $\mathrm{pH}$. However, the prevalence of symptomatic stone disease in TPM users is generally perceived to be low. This study was undertaken to assess in topiramate-treated patients the prevalence of symptomatic nephrolithiasis (by history) and of asymptomatic nephrolithiasis by computed tomography (CT) scan. Topiramate users were identified from a database of patients with neurological disorders at a single university hospital. Among 75 topiramate-treated adult patients with a median daily dose of $300 \mathrm{mg}$ and median treatment duration of 48 months, the prevalence of symptomatic nephrolithiasis was $10.7 \%$. In a subset of topiramate-treated patients and no history of symptomatic stone disease, the prevalence of asymptomatic nephrolithiasis detected by CT scan was $20 \%$. The prevalence of symptomatic

(C) Springer-Verlag 2010

Correspondence to: Naim M. Maalouf, Naim. Maalouf@ut southwestern.edu.

Present Address: J. P. Langston, Division of Urologic Surgery, University of North Carolina, Department of Surgery, Chappell Hill, $\mathrm{NC}$, USA 
nephrolithiasis with long-term topiramate use is higher than reported in short-term studies.

Furthermore, clinical prevalence is underestimated due to asymptomatic nephrolithiasis.

\section{Keywords}

Nephrolithiasis; Prevalence; Topiramate; Kidney stones

\section{Introduction}

Topiramate (TPM) is a pharmacological agent approved for the treatment of partial or primary generalized tonic-clonic seizures and prophylaxis of migraine headaches [1-4]. TPM is also being investigated or prescribed in an off-label fashion for an increasing number of conditions including bipolar disorder, alcoholism, smoking cessation, obesity and binge eating, type 2 diabetes, bulimia nervosa, post traumatic stress disorder, infantile spasms, neuropathic pain, cluster headache, and cocaine dependence [5-14]. In 2008 alone, over 7 million prescriptions for TPM were filled in the United States [15].

Among its multiple pharmacological actions, TPM inhibits renal carbonic anhydrase, leading to metabolic acidosis [16]. The resulting hypocitraturia, elevated urinary $\mathrm{pH}$, and hypercalciuria have been shown to increase urinary saturation with respect to brushite [16] and predispose TPM users to kidney stone formation [5]. However, most clinicians are unaware of TPM-associated nephrolithiasis [5]. In the short-term clinical studies that led to its approval by the Food and Drug Administration (FDA), 1.2-1.5\% of TPM-treated patients developed kidney stones [17]. Considerably higher rates of symptomatic stones have been described with long-term use and possibly with higher doses [18-20]. The escalating FDAapproved and almost unquantifiable off-label use of TPM underscores the need to estimate the true stone prevalence in this population.

We explored this question by utilizing an existing database of TPM-treated patients to retrospectively identify the prevalence of symptomatic nephrolithiasis. We further explored the prevalence of asymptomatic (silent) nephrolithiasis among TPM-users without history of stones.

\section{Materials and methods}

This investigation consisted of two components: a retrospective study estimating the prevalence of symptomatic kidney stone disease in TPM-treated patients and a prospective study in a cohort of TPM-treated individuals with no symptomatic kidney stone disease exploring the prevalence of asymptomatic nephrolithiasis by computed tomography (CT) scan. All studies were reviewed and approved by the institutional review board of UT Southwestern Medical Center.

Information for the retrospective study was obtained from an electronic database consisting of 15,000 adults from the UT Southwestern Department of Neurology's Epilepsy Monitoring Unit. The retrospective survey included telephone contact with TPM-treated patients, and included questions regarding age, ethnicity, gender, height, weight, total daily 
dosage of TPM, and total duration of TPM treatment. Kidney stone episodes were defined by history of spontaneous stone passage, urological interventions for stone disease, and/or radiological evidence of kidney stones. Included in the retrospective study were mainly patients with seizure disorder and a few with migraine headache or mood disorder, all of whom were treated with TPM. Exclusion criteria included subjects with a history of kidney stone disease preceding TPM use, use of other carbonic anhydrase inhibitors, history of recurrent urinary tract infection, immobility, and subjects with an indwelling urinary catheter.

For the prospective study, patients with no history of symptomatic nephrolithiasis were invited to undergo a non-contrast CT scan of the abdomen. All subjects provided informed consent, and were aware of the risk of radiation exposure from CT scan. CT scans were reviewed blindly by a radiologist.

\section{Statistical analysis}

Non-parametric tests were performed due to the skewed distribution of some variables for which results were expressed as median with interquartile range. The results of stone forming and non-stone forming groups on TPM were compared using the Student's $t$ test. Statistical analysis was performed using SAS, version 9.1.3 (SAS Institute, Cary, NC, USA).

\section{Results}

\section{Retrospective prevalence study}

From an electronic database of 15,000 total patients, 150 were identified as treated with TPM. Out of these, we successfully contacted 75 patients by telephone for the survey. The demographic characteristics including age and gender distribution did not differ between the patients who could not be contacted and those patients included in this study (Fig. 1). Of the 75 TPM-treated patients who were contacted, 62 had seizure disorders, 10 had migraine headaches, 2 had both seizure disorders and migraine headaches, and 1 suffered from a mood disorder. 8 out of the 75 total TPM-treated subjects reported kidney stones after starting TPM while 67 described no symptomatic stone disease (Fig. 1), resulting in a prevalence of $10.7 \%$.

There were no statistically significant differences in gender distribution, median age, height, weight, and BMI between the 8 TPM-treated patients who formed stones and the remaining 67 patients who did not develop symptomatic kidney stones (Table 1). The median duration of TPM treatment was numerically higher in stone formers compared with non-stone formers, but did not achieve statistical significance (48 vs. 24 months, $p=0.44$ ). The median daily dosage of TPM treatment for stone forming subjects was similar in stone formers and non-stone formers (Table 1). Stone analysis was available on one stone former, and consisted of $90 \%$ calcium phosphate (apatite) and $10 \%$ calcium oxalate monohydrate.

\section{Prospective imaging study}

Fifteen of the 67 patients with no history of symptomatic nephrolithiasis from the retrospective survey were evaluated by CT scan of the abdomen. These 15 patients were 
representative of the overall population with a mean age of 45 years, average TPM dose of $320 \mathrm{mg} /$ day and average duration of TPM treatment of 43 months. On non-contrast CT scan of the abdomen, 3 out of 15 patients (or 20\%) were identified to have kidney stones. One patient had three non-obstructive stones $(4 \times 4,3 \times 2$ and $3 \times 1 \mathrm{~mm})$, another patient had a single non-obstructive stone $5 \times 3 \mathrm{~mm}$ stone (Fig. 2), while the third patient had a single punctuate $(<2 \mathrm{~mm})$ stone. There were no differences in terms of demographic characteristics when comparing TPM-users with and without asymptomatic stones (Table 2). There was a tendency toward longer treatment duration among silent stone formers, although this did not reach statistical significance (60 vs. 43 months, $p=0.26$ ).

\section{Discussion}

Significant gaps persist in our understanding of TPM-associated nephrolithiasis, including the true prevalence of this complication. The goal of this study was to quantify the prevalence of nephrolithiasis with TPM use. In our retrospective survey, we observed the prevalence of symptomatic nephrolithiasis among long-term TPM-users to be $10.7 \%$, which is significantly higher than reported in published short-term studies [17-19]. Moreover, asymptomatic nephrolithiasis was seen in a sizable proportion of TPM-users.

The pharmacological actions of TPM are diverse [21] and include carbonic anhydrase inhibition, a property thought to account for the heightened risk of stone formation. When renal proximal tubule carbonic anhydrases are inhibited by TPM, systemic acidosis ensues from the reduction of bicarbonate reabsorption, and the increase in final urine $\mathrm{pH}$ from proximal tubule bicarbonate leak is a key risk factor for calcium phosphate stone formation [22]. Furthermore, renal citrate reabsorption and/or metabolism is likely enhanced possibly due to proximal tubule intracellular acidosis, resulting in hypocitraturia which heightens the risk of calcium oxalate and calcium phosphate stone formation.

Short-term prospective and retrospective clinical trials have reported the prevalence of symptomatic kidney stones to be $1-2 \%$ in patients treated with TPM [17]. However, in the present study we observed that the rate of nephrolithiasis in TPM-treated adults was at least fivefold higher at $10.7 \%$. In the majority of the previous studies, the duration of treatment ranged between 6 and 15.8 months, which was shorter than in our study [17-19]. One advantage of this study over previous ones is that stone prevalence was established by a history of spontaneous kidney stones and/or urological interventions for the retrieval of kidney stones. No explanation was made in any of the prior studies regarding a history of pre-existing kidney stones. Furthermore, no specific information was given explaining how the stone episodes were diagnosed. In fact, in one report, urogenital symptoms such as discomfort were recorded as stone incidence [17]. Another strength of the second part of our study is that absence of stones was proven by CT scan of abdomen. The prevalence of kidney stones in this study is consistent with one previous prospective, double blind, placebo-control, multi-center, randomized clinical trial which reported kidney stone occurrence in $9.1 \%$ of subjects with amyotrophic lateral sclerosis [20], albeit, that study was conducted at a higher TPM dose of up to $800 \mathrm{mg} /$ day compared to our retrospective study in which the dose ranged between $150-400 \mathrm{mg} / \mathrm{day}$. It is also important to state that our estimate may still not accurately represent the true prevalence of nephrolithiasis with 
prolonged TPM use since a long duration of treatment may be necessary to form stones. In fact, there was tendency for greater duration of TPM use among stone formers than nonstone formers in our study, although this did not reach statistical significance.

Limitations of this study include the relatively small number of TPM-treated patients, which may in part have limited the power of the study. Our study design does not permit to definitely prove that topiramate was the cause of stone formation in any of the patients, nor was there a control group for comparison. In patients with asymptomatic nephrolithiasis, it is possible that the stones discovered on CT scan preceded TPM therapy. Nevertheless, the prevalence of asymptomatic stones in our TPM-treated cohort is significantly higher than that of 3.2-10.7\% reported in the general US population [23-26]. Systematic survey of all patients given TPM by imaging in a research setting should be informative in providing a true prevalence.

\section{Conclusions}

The previously reported low prevalence of nephrolithiasis with TPM treatment is likely an underestimate. This is particularly pertinent in view of the escalating number of patients embarking on long-term use of this drug and the cumulative number of patients on this therapy in the population with time. Therefore, a $10 \%$ prevalence may represent a very large number of patients. The study of a larger number of patients, an accurate assessment of the true prevalence of nephrolithiasis, and refined laboratory physico-chemical profiles will be needed to further define at risk patients on TPM. The elucidation of these factors may then lead to the development of prevention and treatment of stone disease in this population especially since, in many cases, TPM is extremely effective in treating the underlying neurologic disorder and TPM discontinuation is not the optimal option.

\section{Acknowledgments}

The authors were supported by the National Institutes of Health grants P01-DK20543 and K23RR21710, and a Seed Grant from the Pak Center of Mineral Metabolism.

\section{References}

1. Elterman RD, Glauser TA, Wyllie E, Reife R, Wu SC, Pledger G. Topiramate YP Study Group. A double-blind, randomized trial of topiramate as adjunctive therapy for partial-onset seizures in children. Neurology. 1999; 52(7):1338-1344. [PubMed: 10227615]

2. Biton V, Montouris GD, Ritter F, Riviello JJ, Reife R, Lim P, Pledger G. Topiramate YTC Study Group. A randomized, placebo-controlled study of topiramate in primary generalized tonic-clonic seizures. Neurology. 1999; 52(7):1330-1337. [PubMed: 10227614]

3. Brandes JL, Saper JR, Diamond M, Couch JR, Lewis DW, Schmitt J, Neto W, Schwabe S, Jacobs D. Topiramate for migraine prevention: a randomized controlled trial. JAMA. 2004; 291(8):965973. [PubMed: 14982912]

4. D’Amico D, Grazzi L, Usai S, Moschiano F, Bussone G. Topiramate in migraine prophylaxis. Neurol Sci. 2005; 26(Suppl 2):s130-s133. [PubMed: 15926010]

5. Vega D, Maalouf NM, Sakhaee K. Increased propensity for calcium phosphate kidney stones with topiramate use. Expert Opin Drug Saf. 2007; 6(5):547-557. [PubMed: 17877442]

6. Stenlof K, Rossner S, Vercruysse F, Kumar A, Fitchet M, Sjostrom L. Topiramate in the treatment of obese subjects with drug-naive type 2 diabetes. Diabetes Obes Metab. 2007; 9(3):360-368.

[PubMed: 17391164] 
7. Toplak H, Hamann A, Moore R, Masson E, Gorska M, Vercruysse F, Sun X, Fitchet M. Efficacy and safety of topiramate in combination with metformin in the treatment of obese subjects with type 2 diabetes: a randomized, double-blind, placebo-controlled study. Int J Obes (Lond). 2007; 31(1): 138-146. [PubMed: 16703004]

8. Rosenstock J, Hollander P, Gadde KM, Sun X, Strauss R, Leung A. A randomized, double-blind, placebo-controlled, multi-center study to assess the efficacy and safety of topiramate controlled release in the treatment of obese type 2 diabetic patients. Diabetes Care. 2007; 30(6):1480-1486. [PubMed: 17363756]

9. Raskin P, Donofrio PD, Rosenthal NR, Hewitt DJ, Jordan DM, Xiang J, Vinik AI. Topiramate vs placebo in painful diabetic neuropathy: analgesic and metabolic effects. Neurology. 2004; 63(5): 865-873. [PubMed: 15365138]

10. Vieta E, Torrent C, Garcia-Ribas G, Gilabert A, Garcia-Pares G, Rodriguez A, Cadevall J, GarciaCastrillon J, Lusilla P, Arrufat F. Use of topiramate in treatment-resistant bipolar spectrum disorders. J Clin Psychopharmacol. 2002; 22(4):431-435. [PubMed: 12172346]

11. Marcotte D. Use of topiramate, a new anti-epileptic as a mood stabilizer. J Affect Disord. 1998; 50(2-3):245-251. [PubMed: 9858083]

12. Johnson BA. Progress in the development of topiramate for treating alcohol dependence: from a hypothesis to a proof-of-concept study. Alcohol Clin Exp Res. 2004; 28(8):1137-1144. [PubMed: 15318111]

13. Cubells JF. Topiramate for cocaine dependence. Curr Psychiatry Rep. 2006; 8(2):130-131. [PubMed: 16539889]

14. Johnson BA, Ait-Daoud N, Akhtar FZ, Javors MA. Use of oral topiramate to promote smoking abstinence among alcohol-dependent smokers: a randomized controlled trial. Arch Intern Med. 2005; 165(14):1600-1605. [PubMed: 16043677]

15. [5 October 2010] 2008 Top 200 branded drugs by total prescriptions. 2009. http:// drugtopics.modernmedicine.com/drugtopics/data/articlestandard//drugtopics/222009/599845/ article.pdf

16. Welch BJ, Graybeal D, Moe OW, Maalouf NM, Sakhaee K. Biochemical and stone-risk profiles with topiramate treatment. Am J Kidney Dis. 2006; 48(4):555-563. [PubMed: 16997051]

17. [30 September 2010] Topamax package insert. http://www.ortho-mcneilneurologics.com/sites/ default/files/shared/pi/topamax.pdf

18. Coppola G, Caliendo G, Veggiotti P, Romeo A, Tortorella G, De Marco P, Pascotto A. Topiramate as add-on drug in children, adolescents and young adults with Lennox-Gastaut syndrome: an Italian multicentric study. Epilepsy Res. 2002; 51(1-2):147-153. [PubMed: 12350390]

19. Coppola G, Capovilla G, Montagnini A, Romeo A, Spano M, Tortorella G, Veggiotti P, Viri M, Pascotto A. Topiramate as add-on drug in severe myoclonic epilepsy in infancy: an Italian multicenter open trial. Epilepsy Res. 2002; 49(1):45-48. [PubMed: 11948006]

20. Cudkowicz ME, Shefner JM, Schoenfeld DA, Brown RH Jr, Johnson H, Qureshi M, Jacobs M, Rothstein JD, Appel SH, Pascuzzi RM, Heiman-Patterson TD, Donofrio PD, David WS, Russell JA, Tandan R, Pioro EP, Felice KJ, Rosenfeld J, Mandler RN, Sachs GM, Bradley WG, Raynor EM, Baquis GD, Belsh JM, Novella S, Goldstein J, Hulihan J. A randomized, placebo-controlled trial of topiramate in amyotrophic lateral sclerosis. Neurology. 2003; 61(4):456-464. [PubMed: 12939417]

21. White HS. Molecular pharmacology of topiramate: managing seizures and preventing migraine. Headache. 2005; 45(Suppl 1):S48-S56. [PubMed: 15833090]

22. Pak CY, Adams-Huet B. Elucidation of factors determining formation of calcium phosphate stones. J Urol. 2004; 172(6 Pt 1):2267-2270. [PubMed: 15538246]

23. Chin M, Mendelson R, Edwards J, Foster N, Forbes G. Computed tomographic colonography: prevalence, nature, and clinical significance of extracolonic Wndings in a community screening program. Am J Gastroenterol. 2005; 100(12):2771-2776. [PubMed: 16393234]

24. Flicker MS, Tsoukas AT, Hazra A, Dachman AH. Economic impact of extracolonic findings at computed tomographic colonography. J Comput Assist Tomogr. 2008; 32(4):497-503. [PubMed: 18664832] 
25. Platt JF, Ellis JH, Korobkin M, Reige K. Helical CT evaluation of potential kidney donors: findings in 154 subjects. AJR Am J Roentgenol. 1997; 169(5):1325-1330. [PubMed: 9353451]

26. Lorenz EC, Vrtiska TJ, Lieske JC, Dillon JJ, Stegall MD, Li X, Bergstralh EJ, Rule AD. Prevalence of renal artery and kidney abnormalities by computed tomography among healthy adults. Clin J Am Soc Nephrol. 2010; 5(3):431-438. [PubMed: 20089492] 


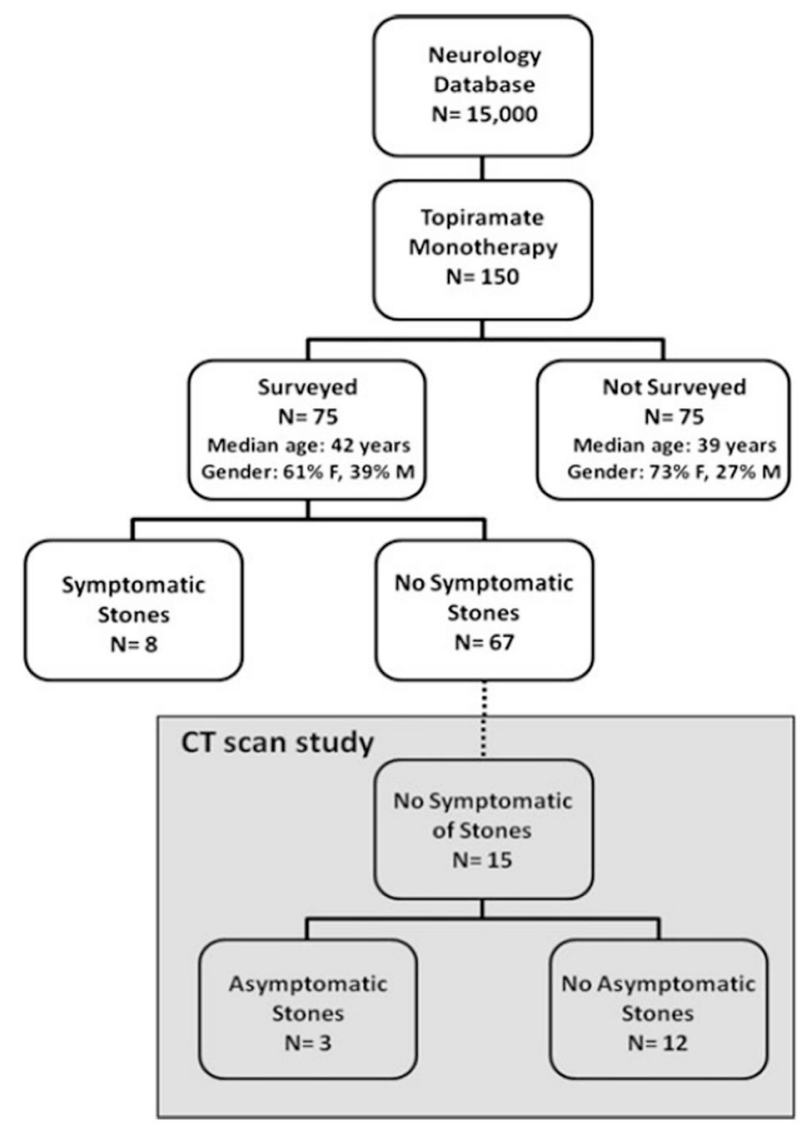

Fig. 1.

Cohort information 


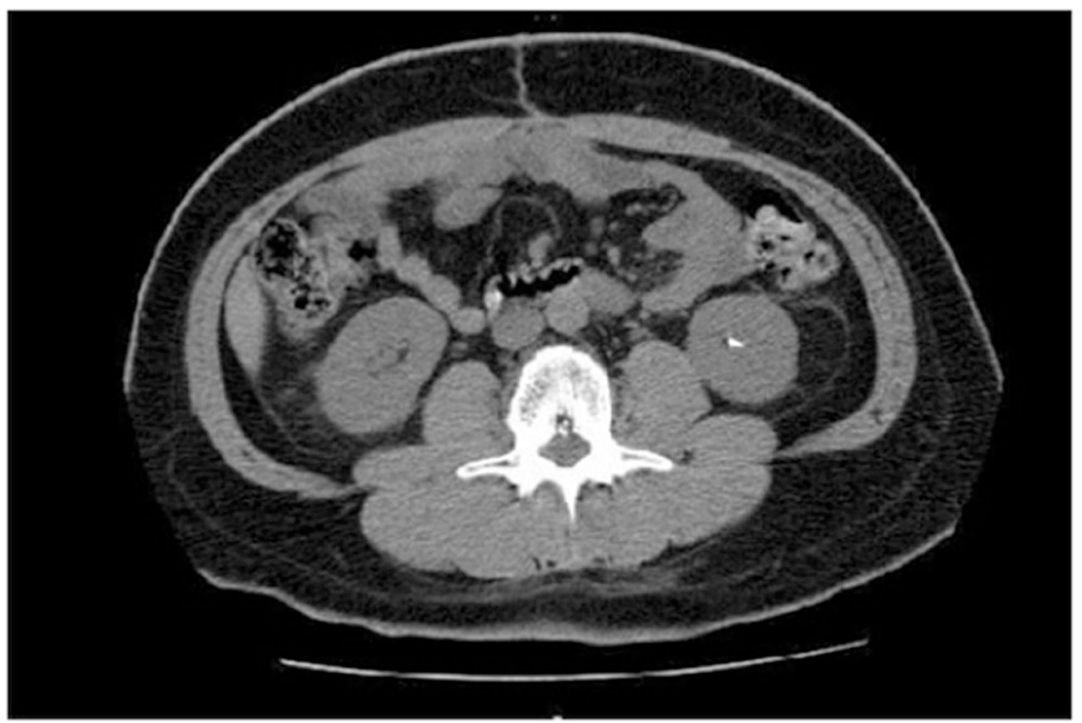

Fig. 2.

Asymptomatic nephrolithiasis in a patient on long-term topiramate 


\section{Table 1}

Demographics of prevalence study

\begin{tabular}{llll}
\hline Variable & Median (interquartile range) & & $\boldsymbol{p}$ value \\
\cline { 2 - 3 } & Patients with symptomatic stone $(\boldsymbol{n}=\mathbf{8})$ & Patients without symptomatic stones $(\boldsymbol{n}=\mathbf{6 7})$ \\
\hline Age (years) & $40(34-62)$ & $40(32-50)$ & \\
Gender & & & 0.45 \\
Female $(\%)$ & 53 & 66 & 0.45 \\
Male $(\%)$ & 47 & 34 & 0.16 \\
Height $(\mathrm{cm})$ & $175(166-183)$ & $167(160-172)$ \\
Weight (kg) & $85(76-95)$ & $78(64-95)$ \\
BMI (kg/m $\left.{ }^{2}\right)$ & $28(24-38)$ & $28(24-33)$ \\
TPM dose (mg/day) & $400(188-425)$ & $300(200-400)$ & 0.45 \\
TPM duration (months) & $48(41-59)$ & $24(18-60)$ & 0.93 \\
\hline
\end{tabular}


Table 2

Demographic characteristics of patients with versus without asymptomatic nephrolithiasis by CT scan

\begin{tabular}{llll}
\hline Variable & Median (interquartile range) & & $p$ value \\
\cline { 2 - 3 } & Patients with asymptomatic stone $(\boldsymbol{n}=\mathbf{3})$ & Patients without asymptomatic stones $(\boldsymbol{n}=\mathbf{1 2})$ & 0.84 \\
\hline Age (years) & $38(37-48)$ & $45(37-52)$ & 0.34 \\
Gender & & & \\
Female $(\%)$ & 33 & 75 & 0.80 \\
Male $(\%)$ & 66 & 25 & 0.27 \\
Weight $(\mathrm{kg})$ & $67(65-79)$ & $61(54-88)$ & 0.42 \\
BMI (kg/m $\left.{ }^{2}\right)$ & $22(21-25)$ & $24(22-30)$ & 0.26 \\
TPM dose (mg/day) & $200(200-300)$ & $350(244-400)$ & $43(26-51)$ \\
TPM duration (months) & $60(48-66)$ & & \\
\hline
\end{tabular}

